\title{
Non-Idealities in the I-V Characteristic of the PV Generators: Manufacturing Mismatch and Shading Effect
}

\author{
Filippo Spertino, Paolo Di Leo and Fabio Corona \\ Politecnico di Torino, Dipartimento di Ingegneria Elettrica \\ Italy
}

\section{Introduction}

A single solar cell can generate an electric power too low for the majority of the applications $(2,5-4 \mathrm{~W}$ at $0,5 \mathrm{~V})$. This is the reason why a group of cells is connected together in series and encapsulated in a panel, known as PhotoVoltaic (PV) module. Moreover, since the output power of a PV module is not so high (few hundreds of watts), then a photovoltaic generator is constituted generally by an array of strings in parallel, each one made by a series of PV modules, in order to obtain the requested electric power.

Unfortunately, the current-voltage (I-V) characteristic of each cell, and so also of each PV module, differs nearly from that of the other ones. The causes can be found in the manufacturing tolerance, i.e. the pattern of crystalline domains in poly-silicon cells, or the different aging of each element of the PV generator, or in the presence of not uniformly distributed shade over the PV array. These phenomena can cause important losses in the energy production of the generator, but they could also lead to destructive effects, such as "hot spots", or even the breakdown of single solar cells. The aim of this chapter is to examine the mismatch in all its forms and effects, exposing some experimental works through simulation and real case studies, in order to investigate the solutions which were thought to minimize the effects of the mismatch.

\section{Series/parallel mismatch in the I-V characteristic}

Firstly, it will be worthy to explain the I-V mismatch in general for the solar cells, making a classification in series and parallel mismatch. In the first case the effect of the different shortcircuit current (and maximum power point current) of each solar cell is that the total I-V characteristic of a string of series-connected cells can be constructed summing the voltage of each cell at the same current value, fixed by the worst element of the string. This means that the string I-V curve is strongly limited by the short-circuit current of the bad cell, and consequently the total output power is much less than the sum of each cell maximum power. This phenomenon is more relevant in the case of shading than in presence of production tolerance. It will be shown that the bad cell does not perform as an open circuit, but like a low resistance (a few ohms or a few tens of ohms), becoming a load for the other solar cells. In particular, it is subject to an inverse voltage and it dissipates power, then if the power dissipation is too high, it will be possible the formation of some "hot spots", with 
degradation and early aging of the solar cell. Furthermore, if the inverse voltage applied to a shaded cell exceeds its breakdown value, it could be destroyed. The worst situation is with the string in short-circuit, when all the voltage of the irradiated cells is applied to the shaded ones. It is clear that the most dangerous case occurs if the shaded cell is only one, while the experience shows that usually with two shaded cells the heating is still acceptable.

The solution adopted worldwide for this problem is the by-pass diode in anti-parallel connection with a group of solar cell for each module. In this way, the output power decreases only of the contribution of the group of bad cells and the inverse voltage is limited by the diode.

In the case of parallel of strings, it is the voltage mismatch which becomes important. The total I-V characteristic can be constructed summing the current of each string at the same voltage value. The total open-circuit voltage will be very close to that of the bad string. The worst case for the bad or shaded string is that one of the open circuit, because it will become the only load for the other strings. Consequently, it will conduct inverse current with unavoidable over-heating, which can put the string in out of service. In the parallel mismatching a diode in series with the string can avoid the presence of inverse currents.

After this basic introduction to the mismatch, the equivalent circuit of a solar cell with its parameters will be illustrated.

\subsection{Solar cell model for I-V curve simulation}

The equivalent circuit of a solar cell with its parameters is a tool to simulate, for whatever irradiance and temperature conditions, the $I-V$ characteristics of each PV module within a batch that will constitute an array of parallel-connected strings of series-connected modules. With this aim, the literature gives two typical equivalent circuits, in which a current source I is in parallel with a non linear diode. $\mathrm{I}_{\mathrm{ph}}$ is directly proportional to the irradiance $\mathrm{G}$ and the area of the solar cell A, simulating the photovoltaic effect, according to the formula

$$
I_{p h}=K_{S} \cdot G \cdot A
$$

Since PV cells and modules are spectrally selective, their conversion efficiency depends on the daily and monthly variations of the solar spectral distribution (Abete et al., 2003) . A way to assess the spectral influence on PV performance is by means of the effective responsivity $\mathrm{K}_{\mathrm{S}}(\mathrm{A} / \mathrm{W})$ :

$$
K_{S}=\frac{\int g(\lambda) \cdot S(\lambda) d \lambda}{\int g(\lambda) d \lambda}
$$

where $S(\lambda)$ is the absolute spectral response of a silicon cell (A/W) and $g(\lambda)$ the irradiance spectrum $\left(\mathrm{W} / \mathrm{m}^{2} \mu \mathrm{m}\right)$.

A suitable software, which calculates the global radiation spectrum on a selected tilted plane, has been used. Apart from month, day and time, the input parameters are meteorological and geographical data: global and diffuse irradiance on horizontal plane $\left(\mathrm{W} / \mathrm{m}^{2}\right)$, ambient temperature $\left({ }^{\circ} \mathrm{C}\right)$, relative humidity $(\%)$, atmospheric pressure $(\mathrm{Pa})$; latitude and longitude. Among the output parameters, it is important the global irradiance spectrum (on the tilted plane) versus wavelength. By the spectral response of a typical mono-crystalline silicon cell, it is possible to calculate $K_{s}$. As an example, Figure 1 shows the quantities $S(\lambda), g_{1}(\lambda)$ and $g_{2}(\lambda)$ at 12.00 of a clear day in winter and summer, respectively. It 
is noteworthy that between 0.9 and $1 \mu \mathrm{m}$, where $S(\lambda)$ is high, the winter spectrum exceeds the summer spectrum. Figure 2 shows the quantities $S(\lambda) \cdot g_{1}(\lambda)$ and $S(\lambda) \cdot g_{2}(\lambda)$, named spectral current density $\delta_{\mathrm{I} 1}$ e $\delta_{\mathrm{I} 2}$, which have units of $\mathrm{A} /\left(\mathrm{m}^{2} \mu \mathrm{m}\right)$. Not only in this example, but in many cases $\mathrm{K}_{\mathrm{S}}$ is higher in winter than in summer and the deviations are roughly $5 \%$.

$g_{2}(\lambda): 7$ August ; $g_{1}(\lambda): 24$ February

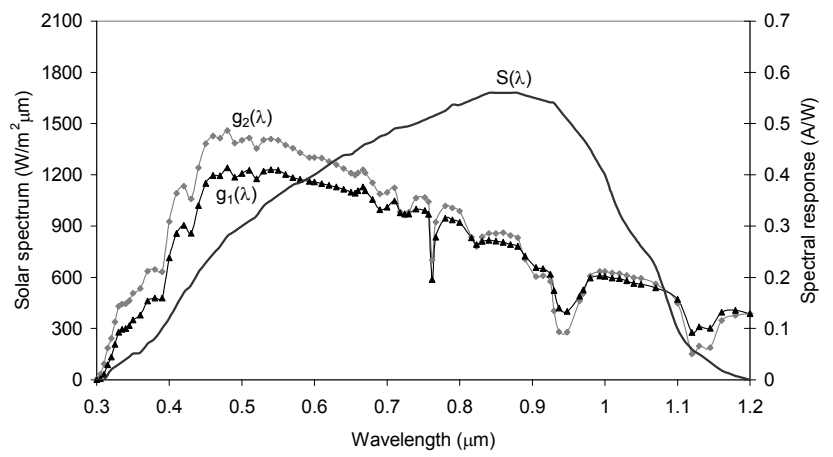

Fig. 1. Comparison of solar spectra in winter and summer.

$\delta_{\mathrm{i} 2}(\lambda): 7$ August ; $\delta_{\mathrm{i} 1}(\lambda): 24$ February

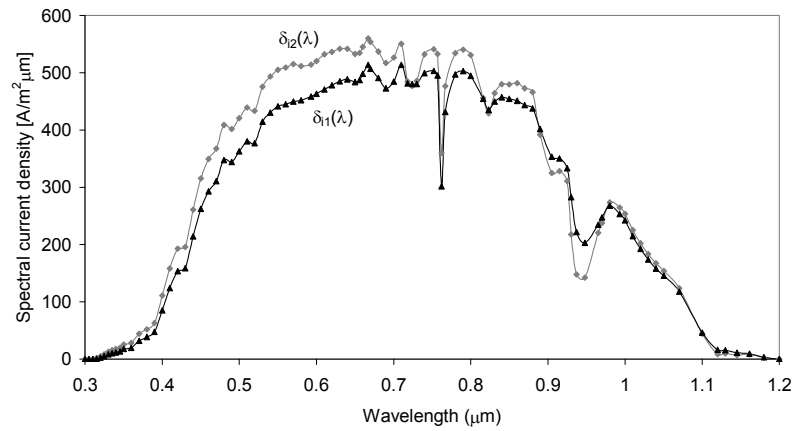

Fig. 2. Comparison of spectral current density in winter and summer.

The rated power of the PV devices is defined at Standard Test Conditions (STC), corresponding to the solar spectrum at noon in the spring/autumn equinox, with clear sky. This global irradiance $\left(\mathrm{G}_{\mathrm{STC}}=1000 \mathrm{~W} / \mathrm{m}^{2}\right)$ is also referred as Air Mass (AM) equal to 1.5.

Then, considering the non linear diode, on the one hand, the first equivalent circuit is based on a single exponential model for the P-N junction, in which the reverse saturation current $I_{o}$ and quality factor of junction $m$ are the diode parameters to be determined:

$$
I_{j}=I_{o} \cdot\left(e^{\frac{q V_{j}}{m k T_{c}}}-1\right)
$$


where $V_{j}$ is the junction voltage, $k$ the Boltzmann constant, $q$ the electron charge and $T_{c}$ the cell temperature.

On the other hand, the second model involves a couple of exponential terms, in which the quality factors assume fixed values ( 1 and 2 usually), whereas $I_{o 1}$ and $I_{o 2}$ must be inserted.

$$
I_{j}=I_{o 1} \cdot\left(e^{\frac{q V_{j}}{m_{1} k T_{c}}}-1\right)+I_{o 2} \cdot\left(e^{\frac{q V_{j}}{m_{2} k T_{c}}}-1\right)
$$

The model with a single exponential is used in this chapter (Fig. 3). In this one, the series resistance $R_{s}$ accounts for the voltage drop in bulk semiconductor, electrodes and contacts, and the shunt resistance $R_{s h}$ represents the lost current in surface paths.

Thus, five parameters are sufficient to determine the behaviour of the solar cell, namely, the current source $I_{p h}$, the saturation current $I_{o}$, the junction quality factor $m$, the series resistance $R_{s}$, the shunt resistance $R_{s h}$. If we examine the silicon technologies, monocrystalline (m-Si), poly-crystalline (p-Si) and amorphous (a-Si), the shape of the $I-V$ curve is mainly determined by the values of $R_{s}$ and $R_{s h}$.

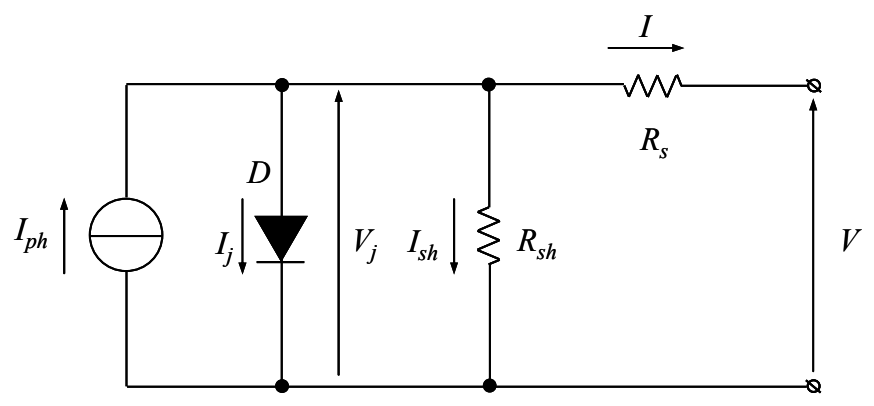

Fig. 3. Equivalent circuit of solar cell with one exponential.

Finally, the dependence on the solar irradiance $G(t)$ and on the cell temperature $T_{c}(t)$ is explained for the ideal PV current $I_{p h}$ and the reverse saturation current $I_{0}$ in the following expression:

$$
\begin{gathered}
I_{p h}=I_{S C \mid S T C} \frac{G}{G_{S T C}}\left[1+\alpha_{T}\left(T_{c}-298\right)\right] \\
I_{0}=I_{0 \mid S T C}\left(\frac{T_{c}}{298}\right)^{3} \frac{e^{-\frac{E_{g}}{k T_{c}}}}{e^{-\frac{E_{g}}{k \cdot 298}}}
\end{gathered}
$$

where $\mathrm{ISC}_{\mathrm{SCTC}}$ is the short-circuit current evaluated at STC $\left(\mathrm{T}_{\mathrm{STC}}=25^{\circ} \mathrm{C}=298 \mathrm{~K}\right), \alpha_{T}$ is the temperature coefficient of $I_{p h}, E_{g}$ is the energy gap and $k$ is the Boltzmann constant. The cell temperature is evaluated by considering a linear dependence on the ambient temperature $T_{a}$ 
and the irradiance G, according to the NOCT definition valid for modules installed in mounting structures which allow the natural air circulation (maximum wind speed equal to $1 \mathrm{~m} / \mathrm{s})$ :

$$
T_{c}=T_{a}+\frac{G}{G_{N O C T}}\left(N O C T-20^{\circ} \mathrm{C}\right)
$$

in which $G_{N O C T}=800 \mathrm{~W} / \mathrm{m}^{2}$. By using the aforementioned model, the PV-array $I(V)$ characteristic, corresponding to the actual irradiance and cell temperature, is calculated on a specific program implemented in MATLAB.

Through this model of a solar cell it is possible to simulate the mismatch due to shading effect on different configurations of a PV generator made of an array of solar panels. Usually the shading effect is studied changing the number of shaded solar cells of a single module for each configuration considered. The current-voltage (I-V) curve is then determined, together with the maximum power available with the shading $\mathrm{P}_{\mathrm{m}}$ ' (normalized with the power $P_{m}$ without shades and defined as $\mu$ ), the power dissipated and the inverse voltage on the shaded solar cells.

For example, the following simulation is relative to a series mismatch due to shading. Let us consider a $35 \mathrm{~W}_{\mathrm{p}}$ rated power PV module of 36 solar cells in poly-crystalline silicon, with a short circuit current of $2.4 \mathrm{~A}$ in STC. Figure 4 shows the I-V curves of:

a. 36 cells totally irradiated;

b. 35 cells totally irradiated;

c. 1 completely shaded cell;

d. 36 cells with 1 shaded cell.

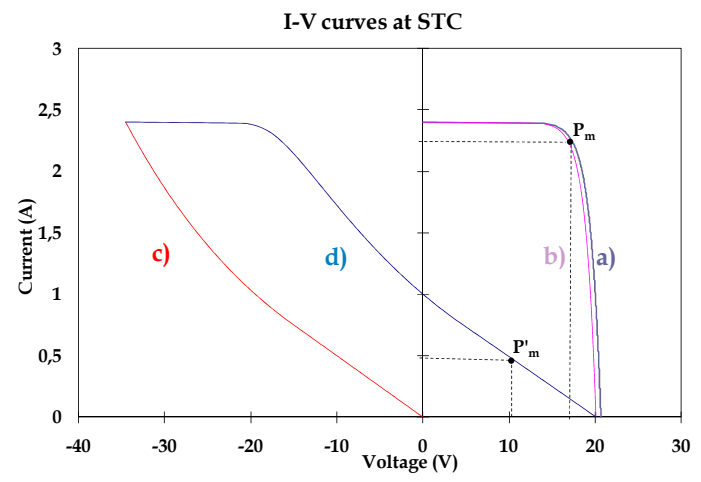

Fig. 4. I-V curves of different number of series-connected solar cells.

In the d) curve the normalized power $\mu$ is reduced significantly (nearly $10 \%$ ) as it is shown in Table 1. In the shaded cell the worst condition, in terms of dissipated power $P_{c}$ and inverse voltage $U_{c}$, occurs when the PV module is in short circuit. Its working point can be obtained from the interception between curve $c$ ) and curve b), in figure 1, if the curve b) is reversed respect the current axis. This point gives the dissipated power and inverse voltage on the shaded cell $\left(\mathrm{U}_{\mathrm{c}}=18 \mathrm{~V}\right.$ e $\left.\mathrm{P}_{\mathrm{c}}=24 \mathrm{~W}\right)$. Raising the number of shaded solar cells $\left(\mathrm{N}_{\mathrm{c}}\right)$ the values of $\mu$, $P_{c}$ and $U_{c}$ shown in table 1 are obtained. It is clear that if $N_{c}$ grows $P_{c}$ and $U_{c}$ decrease, namely the working conditions of the PV module are less dangerous for the solar cells. 


\begin{tabular}{c|c|c|c}
\hline$N_{c}$ & $\mu$ & $P_{c}[W]$ & $U_{c}[V]$ \\
\hline 1 & 0.11 & 24 & 18 \\
2 & 0.06 & 4.3 & 9.2 \\
3 & 0.04 & 1.8 & 6.1 \\
4 & 0.03 & 1 & 4.4 \\
18 & 0 & 0 & 0 \\
36 & 0 & 0 & 0 \\
\hline
\end{tabular}

Table 1. Normalized power of the PV module $\mu$, dissipated power $\mathrm{P}_{\mathrm{c}}$ and inverse voltage $\mathrm{U}_{\mathrm{c}}$ on shaded solar cell, under STC, depending on the number of shaded solar cells.

\section{Manufacturing I-V mismatch}

Considering at first the mismatch among PV modules due to production tolerance, a first study is presented in the paper (Abete et al., 1998) in which an experimental set up has been developed to detect the mismatching of the current-voltage characteristics between a reference PV module and another one under test, in the same environmental conditions. Two dual bridge circuits have been set up, one with series and the other one with parallel connected modules, which have produced the direct measurement of the difference characteristic and the mismatching parameters. Therefore it has been achieved a better accuracy as regard to the indirect determination of the difference from the two I-V characteristics. The measuring circuits reported could be profitably employed for optimum module connection in the array, manufacturer quality control, customer acceptance testing and field test on PV array.

\subsection{Production tolerance detection}

The optimum performance of a photovoltaic module or array is achieved if the currentvoltage $\mathrm{I}(\mathrm{U})$ characteristics of the solar cells in the module or the $\mathrm{I}(\mathrm{U})$ characteristics of the modules in the array are identical (matched). Otherwise, that is when an I-U mismatch occurs due to manufacturing tolerance, the electrical output power of the PV array decreases and the increasing internal power losses may cause "hot spots" up to the failure of the module with lower performance. The mismatch of the $\mathrm{I}(\mathrm{U})$ curves of PV modules is measured by the difference between two $\mathrm{I}(\mathrm{U})$ characteristics, one of a reference module and the other of a testing module, in the same ambient conditions. For the direct measurement of this difference curve (to achieve uncertainty lower than with indirect measurement), two dual measuring circuits are presented, one with series and the other with parallel connected modules.

To obtain this difference between the reference and the testing $\mathrm{I}(\mathrm{U})$ curves, it is required to measure the voltage difference of series connected modules, for equal current value, and the current difference of parallel connected modules for equal voltage value. The two measuring circuits can be regarded as a bridge comparing, point by point, the dynamic $\mathrm{I}(\mathrm{U})$ characteristics of two PV modules, the reference and the other under test. In the first circuit ("series type") the PV modules are series connected: in case of mismatch, the voltage output measurement of the unbalanced bridge, for each current value, is directly proportional to the difference of the module's voltages $\Delta \mathrm{U}$. This $\Delta \mathrm{U}$ vs. current I represents the difference characteristic $\mathrm{U}_{2}(\mathrm{I})-\mathrm{U}_{1}(\mathrm{I})$. In the dual circuit ("parallel type") the 
PV modules are parallel connected: in case of mismatch, the voltage output measurement of the unbalanced bridge, for each voltage value, is directly proportional to the difference of the module's currents $\Delta \mathrm{I}$. This $\Delta \mathrm{I}$ vs. voltage $\mathrm{U}$ represents the voltage difference characteristics $\mathrm{I}_{2}(\mathrm{U})-\mathrm{I}_{1}(\mathrm{U})$.

Fig. 5 and Fig. 6 show the series and parallel bridge measuring circuits. Each bridge has two active branches constituted by two modules, $\mathrm{PV}_{1}$ (reference) and $\mathrm{PV}_{2}$ (testing), which are subject to the same irradiance $G$ and cell temperature $T$. The other two branches of each bridge are two equal resistors, $R_{s}$ with high resistance in Fig. 5 and $R_{p}$ with low resistance in Fig. 6, such as to have a negligible loading effect on the $\mathrm{I}(\mathrm{U})$ characteristics of $\mathrm{PV}_{1}$ and $\mathrm{PV}_{2}$ modules. $C$ is a capacitor such as to give a suitable $\mathrm{du} / \mathrm{dt}$, i.e., not so quick to interfere with the parasitic junction capacitance of the solar cells and not so slow to permit the variation of the ambient conditions. Usually, values around a few millifarad are adequate. The PR devices are Hall-effect probes for accurate and non-intrusive measurement of current. At closing of switch s, the transient charge of the capacitor $C$ provides, in a single sweep, the $\mathrm{I}(\mathrm{U})$ dynamic curves of the two modules.

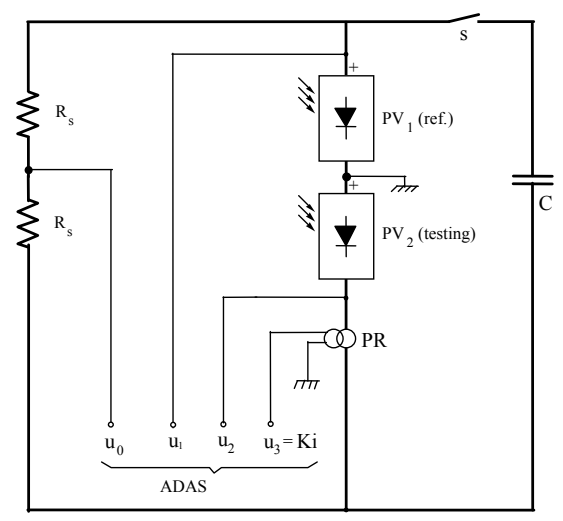

Fig. 5. "Series type" bridge measuring circuit.

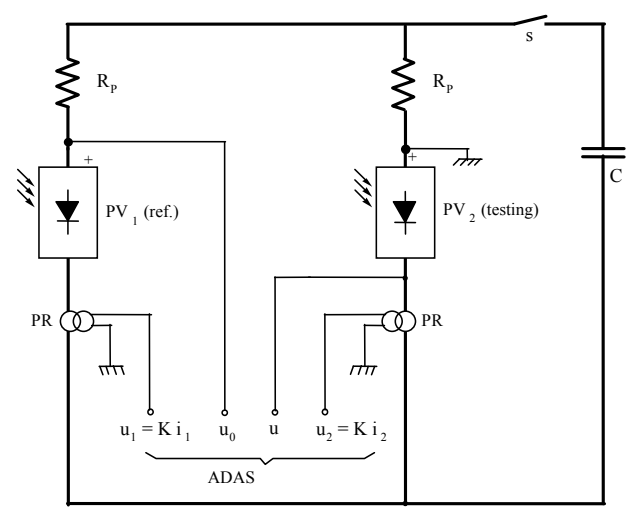

Fig. 6. "Parallel type" bridge measuring circuit. 
The circuit analysis proves that:

- $\quad$ in the series circuit, for each current value, the voltage output $\mathrm{U}_{0}$ of the unbalanced bridge measures the difference $\Delta \mathrm{U}$ of the two module's voltages by $\Delta \mathrm{U}=\mathrm{U}_{0}\left(2+\mathrm{R}_{\mathrm{s}} / \mathrm{R}_{0}\right)$;

- in the parallel circuit, for each voltage values, the voltage output $U_{0}$ of the unbalanced bridge measures the difference $\Delta \mathrm{I}$ of the two modules currents by $\Delta \mathrm{I}=\mathrm{U}_{0}\left(1 / \mathrm{R}_{\mathrm{p}}+2 / \mathrm{R}_{0}\right)$ with $R_{0}$ input resistance of the instrument which measures the voltage output $U_{0}$.

Therefore, the measurement of the voltage difference $\Delta \mathrm{U}$ vs. the current I gives the difference curve of the series connected modules; the measurement of the current difference $\Delta \mathrm{I}$ vs. the voltage $\mathrm{U}$ gives the difference curve of the parallel connected modules. For mismatch assessment, besides the difference of open circuit voltages $\Delta \mathrm{U}_{\text {oc }}$ and of short circuit currents $\Delta \mathrm{I}_{\mathrm{sc}}$, it is profitable, in the maximum power point $\mathrm{P}_{\mathrm{M}}=\left(\mathrm{I}_{\mathrm{M}}, \mathrm{U}_{\mathrm{M}}\right)$ of the reference module, to know the following parameters:

- the voltage difference $\Delta \mathrm{U}_{\mathrm{M}}$ and the power reduction $\Delta \mathrm{P}_{\mathrm{MI}}=\mathrm{I}_{\mathrm{M}} \Delta \mathrm{U}_{\mathrm{M}}$ for series connected modules;

- the current difference $\Delta \mathrm{I}_{\mathrm{M}}$ and the power reduction $\Delta \mathrm{P}_{\mathrm{MU}}=\mathrm{U}_{\mathrm{M}} \Delta \mathrm{I}_{\mathrm{M}}$ for parallel connected modules.

These quantities $\Delta \mathrm{U}_{\mathrm{M}}, \Delta \mathrm{P}_{\mathrm{MI}}, \Delta \mathrm{I}_{\mathrm{M}}$ and $\Delta \mathrm{P}_{\mathrm{MU}}$ can be assumed as "mismatch parameters".

The measuring signals of the circuits in Fig. 5 and Fig. 6 (K current probe constant), with a suitable sampling rate $(10-100 \mathrm{kSa} / \mathrm{s})$, are digitized by an Automatic Data Acquisition System (ADAS). This ADAS processes the signals for providing current-voltage curves of the PV modules, the difference characteristics and the mismatch parameters. These experimental results, concerning series and parallel connected polycrystalline silicon modules, are shown respectively in Fig. 7 and Fig. 8. In Fig. 7 the testing module $\mathrm{I}_{\left(\mathrm{U}_{2}\right) \text { curve }}$ extends as far as the second quadrant, while the reference module $\mathrm{I}\left(\mathrm{U}_{1}\right)$ curve does not run through all the first quadrant. This proves that the short circuit currents of the two modules are different and consequently the testing module can operate as a load of the reference module. In Fig. 8, likewise, the testing module $\mathrm{I}_{2}(\mathrm{U})$ curve extends as far as the fourth quadrant, while the reference module $\mathrm{I}_{1}(\mathrm{U})$ curve does not run through all the first quadrant. This proves that the open circuit voltages of the two modules are different and thus the testing one can operate as a load. Once the power reduction are $\Delta \mathrm{P}_{\mathrm{MI}}$ and $\Delta \mathrm{P}_{\mathrm{MU}}$ are measured, it is possible to choose the connection of the modules in the array to achieve the optimum performance. Finally, the presented circuits can be profitably employed in manufacturer quality control and customer acceptance testing.

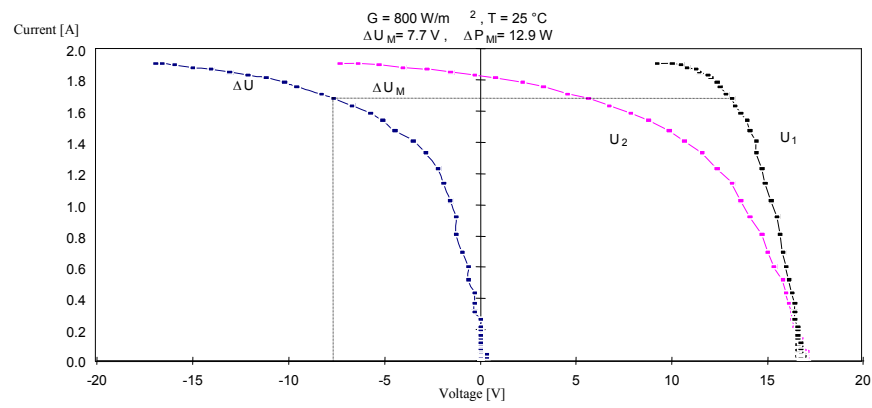

Fig. 7. Experimental results with series connected polycrystalline silicon modules. 


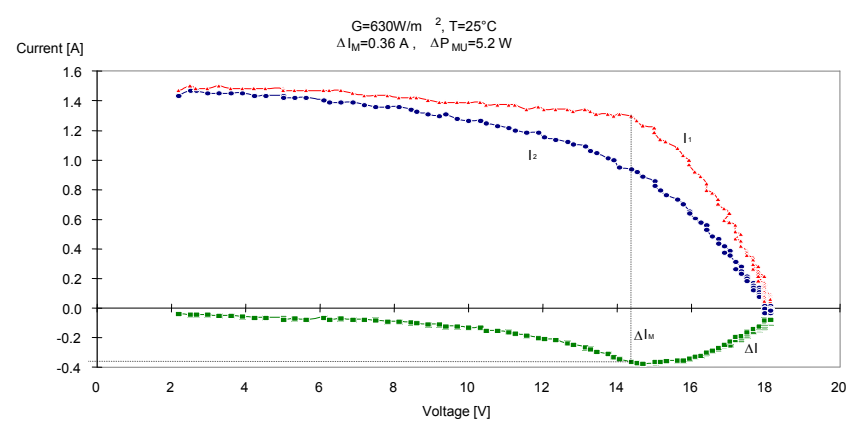

Fig. 8. Experimental results with parallel connected polycrystalline silicon modules.

\subsection{Manufacturing I-V mismatch and reverse currents in large Photovoltaic arrays}

As an example of the consequences of the production tolerance in large PV plants, a brief summary of a study on this topic is reported here. This work has dealt with the currentvoltage mismatch consequent to the production tolerance as a typical factor of losses in large photovoltaic plants (Spertino \& Sumaili, 2009). The results have been simulated extracting the parameters of the equivalent circuit of the solar cell for several PV modules from flash reports provided by the manufacturers. The corresponding I-V characteristic of every module has been used to evaluate the behavior of different strings and the interaction among the strings connected for composing PV arrays. Two real crystalline silicon PV systems of $2 \mathrm{MW}$ and $20 \mathrm{~kW}$ have been studied. The simulation results have revealed that the impact of the I-V mismatch is negligible with the usual tolerance, and the insertion of the blocking diodes against reverse currents can be avoided with crystalline silicon technology. On the other hand, the experimental results have shown a remarkable power deviation $(3 \%$ $4 \%$ ) with respect to the rated power, mainly due to the lack of measurement uncertainty in the manufacturer flash reports.

\section{Optimal configuration of module connections for minimizing the shading effect in multi-rows PV arrays}

In another study, the periodic shading among the rows in the morning and in the evening in grid-connected PV systems, installed e.g. on the rooftop of buildings, has been investigated (Spertino et al. 2009). This phenomenon is quite common in large PV plants, in fact often the designer does not take into account this shading when he decides the module connections in the strings, the number of modules per string and the arrangement, according to the longest side of the modules, in horizontal or vertical direction. The study has discussed, by suitable comparisons, various cases of shading pattern in PV arrays from multiple viewpoints: power profiles in clear days with 15-min time step, daily energy as a monthly average value for clear and cloudy days. The simulation results have proved that, with simple structure of the array and important amount of shading, it is better to limit the shading effect within one string rather than to distribute the shading on all the strings: the gains are higher than $10 \%$ in the worst month and $1 \%$ on yearly basis. Contrary, with more complex structure of the array and low amount of shading, it is practically equivalent to concentrate or to distribute 
the shading on all the strings. Finally, in the simulation conditions the impact of the shading losses on yearly basis is limited to $1-3 \%$.

\subsection{Analysis of some shading patterns}

In order to establish some guidelines for minimising the shading effect in multi-rows PV arrays, a comparison among different configurations of module connections is carried out within simplifying assumptions, i.e., all the shaded modules are located only in a single string vs. the shaded modules are equally distributed in all the strings. In particular, the shading implies the collection of the diffuse irradiance without the direct or beam irradiance; thus, the parameters which determine the behaviour of the PV arrays in these conditions are:

- $\quad \mathrm{N}_{\mathrm{S}}$ : number of series connected modules per string $\left(\mathrm{N}_{\mathrm{S}}>1\right.$ otherwise the meaning is vanishing);

- $\quad \mathrm{N}_{\mathrm{P}}$ : number of parallel connected strings per array $\left(\mathrm{N}_{\mathrm{P}}>1\right.$ otherwise the meaning is vanishing);

- $\quad \mathrm{N}_{\mathrm{Ssh}}$ (one_str): number of shaded modules in the case of shading concentrated in a single string;

- $\quad N_{\text {ssh }}$ (all_str): number of shaded modules per each string in the case of shading distributed in all the strings.

All the comparisons are performed by satisfying the equation:

$$
\frac{N_{S s h}(\text { one_str })}{N_{S}}=N_{P} \cdot \frac{N_{S s h}(\text { all_str })}{N_{S}}
$$

Obviously, the previous parameter $\mathrm{N}_{\mathrm{Ssh}}\left(\right.$ all_str) $\geq 1$ only if $\mathrm{N}_{\mathrm{P}} \leq \mathrm{N}_{\mathrm{S}}$.

In our study, the chosen arrays are two, the first one with usual number of modules per string $\left(\mathrm{N}_{\mathrm{S}}=16\right)$ and low number of parallel strings $\left(\mathrm{N}_{\mathrm{P}}=4\right)$ concerns a decentralized inverter (Figures 9 and 10), whereas the second one deals with a centralized inverter $\left(\mathrm{N}_{\mathrm{S}}=16, \mathrm{~N}_{\mathrm{P}}=8\right.$ in Figures 11 and 12). In order to gain deeper understanding, the pattern of shading (i.e. modules subject to diffuse radiation without beam radiation) can be:

1. either one or a half shaded string in the array, i.e., $\mathrm{N}_{\mathrm{Ssh}}$ (one_str) $=16$ or $\mathrm{N}_{\mathrm{Ssh}}$ (one_str) $=8$;

2. whereas only one or more modules with shading for every string of the array, i.e., $\mathrm{N}_{\text {Ssh }}\left(\right.$ all_str) $=1$ or $\mathrm{N}_{\text {Ssh }}($ all_str) $=4$.

On one hand, in the first array with $25 \%$ - shading amount the situations are: 4 shaded modules in every string (conf. 1 in Figure 9) vs. all the 16 modules shaded in the same string (conf. 2 in Fig. 10). The eq. (8) becomes

$$
\frac{N_{\text {Ssh }}(\text { one_str })}{N_{S}}=N_{P} \cdot \frac{N_{\text {Ssh }}(\text { all_str })}{N_{S}}=1
$$

with $\mathrm{N}_{\mathrm{Ssh}}\left(\right.$ one_str) $=16$ and $\mathrm{N}_{\mathrm{Ssh}}($ all_str) $=4$ corresponding to the maximum number of shaded modules per string in this example. In Figure 9 in every string, even if there are both shaded modules (four) and totally irradiated modules (twelve), it is assumed the same temperature for uniformity reasons and this one is equal to the temperature of the totally irradiated modules. Consequently, the I-V curve can be calculated. 
On the other hand, in the second array with $6.25 \%$ - shading amount the situations are 8 shaded modules in the same string (half a string in Conf. 4 of Fig. 12) vs. one shaded module for every string (Conf. 3 of Fig. 11), i.e., the eq. (8) becomes

$$
\frac{N_{S s h}(\text { one_str })}{N_{S}}=N_{P} \cdot \frac{N_{S s h}(\text { all_str })}{N_{S}}=\frac{1}{2}
$$

with $\mathrm{N}_{\text {Ssh }}\left(\right.$ one_str) $=8$ and $\mathrm{N}_{\text {Ssh }}($ all_str) $=1$ corresponding to the minimum number of shaded modules.

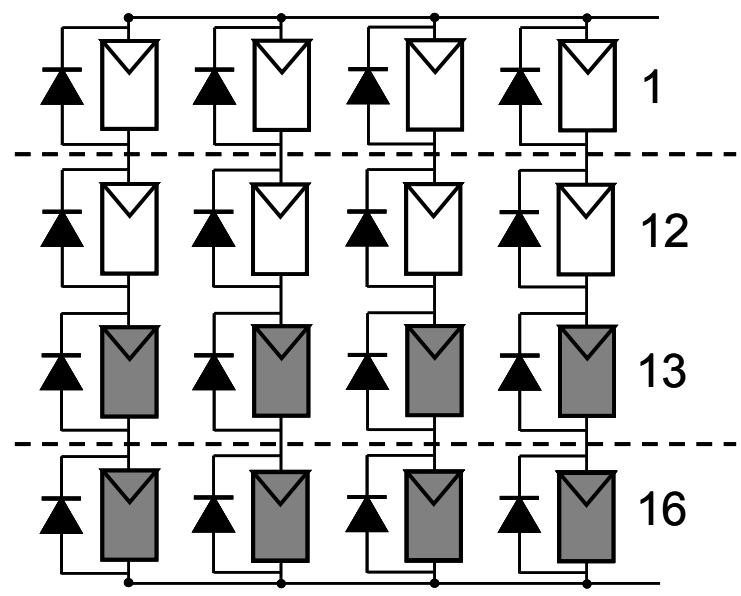

Fig. 9. Array $\left(\mathrm{N}_{S}=16, \mathrm{~N}_{\mathrm{P}}=4\right)$ with shading patterns - Configuration 1

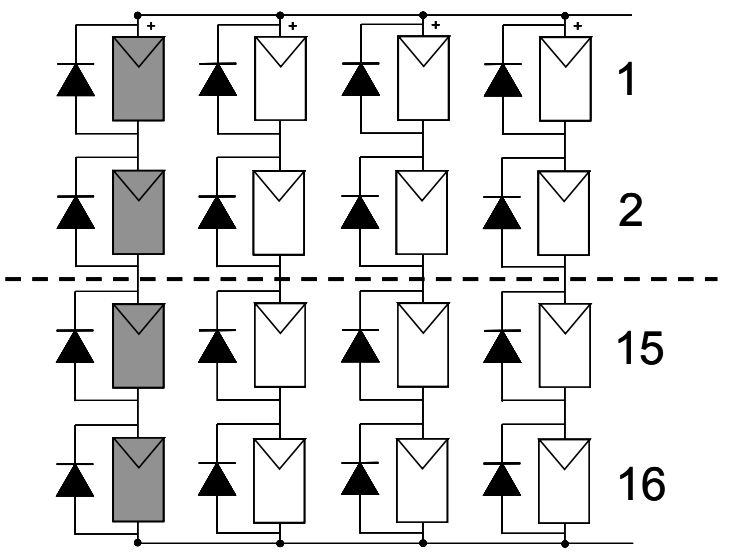

Fig. 10. Array $\left(\mathrm{N}_{\mathrm{S}}=16, \mathrm{~N}_{\mathrm{P}}=4\right)$ with shading patterns - Configuration 2 


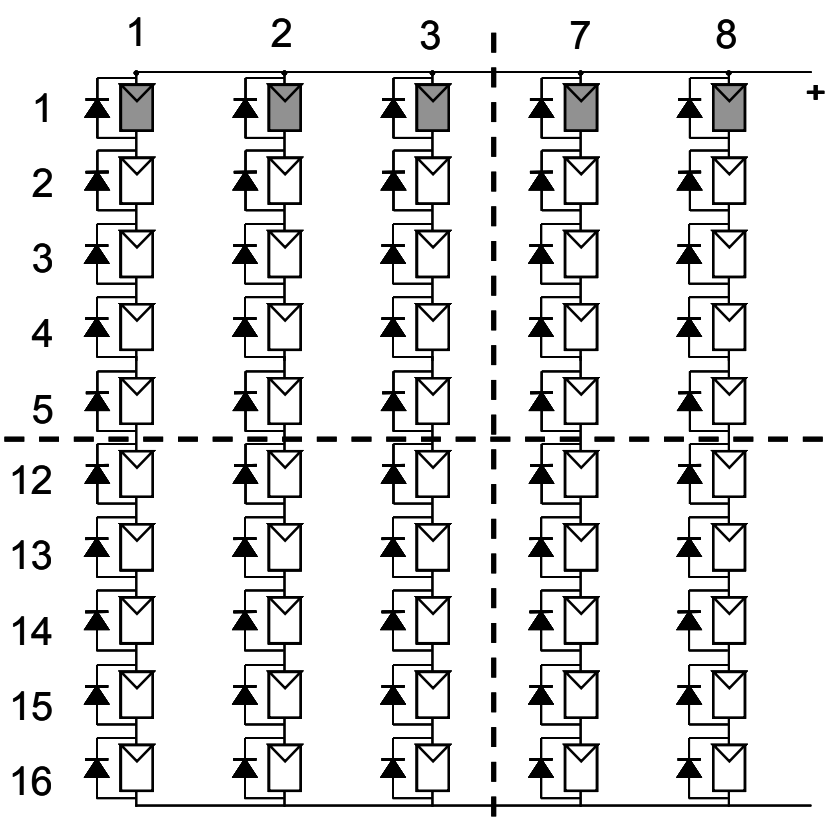

Fig. 11. Array $\left(\mathrm{N}_{S}=16, \mathrm{~N}_{\mathrm{P}}=8\right)$ with shading patterns - Configuration 3

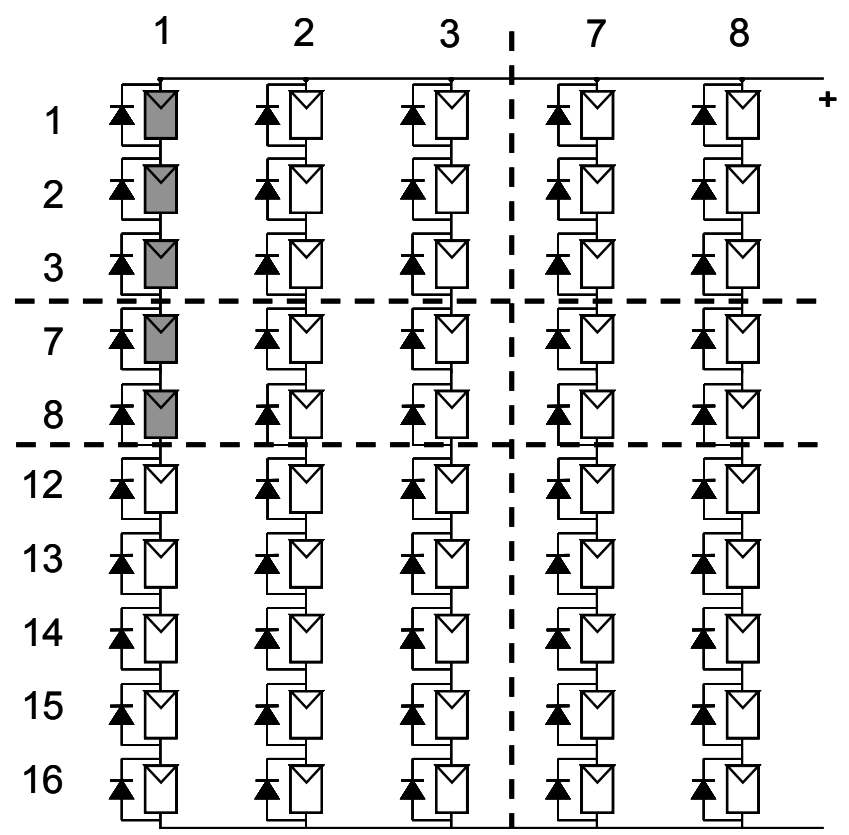

Fig. 12. Array $\left(\mathrm{N}_{\mathrm{S}}=16, \mathrm{~N}_{\mathrm{P}}=8\right)$ with shading patterns - Configuration 4 


\subsection{Simulation results of the considered shading patterns}

The study cannot be limited to the irradiance values in the clear days, but requires the simulation of real-sky conditions by using an average day which takes into account both clear and cloudy days (e.g. Page and Liu-Jordan models). In this case, the PVGIS tool, available on the web-site of JRC of the European Commission, is used. Simulation results are presented in the following with reference to a South-Italy location (latitude $\varphi \approx 41.5^{\circ}$, tilt angle $\beta=15^{\circ}$ for maximum installation density and azimuth $\psi=30^{\circ} \mathrm{W}$ ). The installation option is the PV-rooftop array in order to earn higher amount of money within the Italian feed-in tariff (partial building integration). The obstruction which produces the shading effect is the balustrade of the building roof: consequently, only the PV-modules of the closest row are subject to the shading because the successive rows are sufficiently separate each other $\left(d>d_{\min }\right.$ in Figure 13 where $d_{\min }$ is calculated on the Winter solstice at noon with Sunheight angle $a)$.

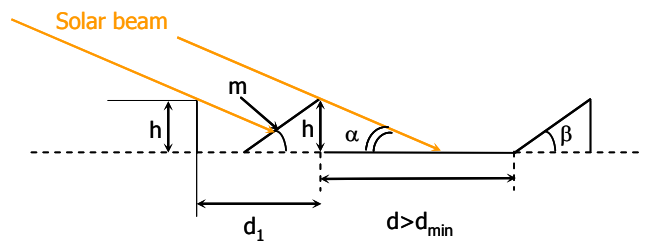

Fig. 13. The row arrangement and the balustrade obstruction with height $h$

The figures 14 and 15 show the two patterns of shading for the first PV array $\left(N_{S}=16, N_{P}=4\right)$ with 4 rows: in the configuration 1 (Fig. 14) there are 4 modules per string in each row and in configuration 2 (Fig. 15) there are all the 16 modules of each string in a single row.

The figures 16 and 17 show the two patterns of shading for the second PV array $\left(N_{S}=16, N_{P}\right.$ $=8$ ) with 16 rows: in the configuration 3 (Fig. 16) there is only one module per string in each row and in configuration 4 (Fig. 17) there are 8 modules of each string in a single row.

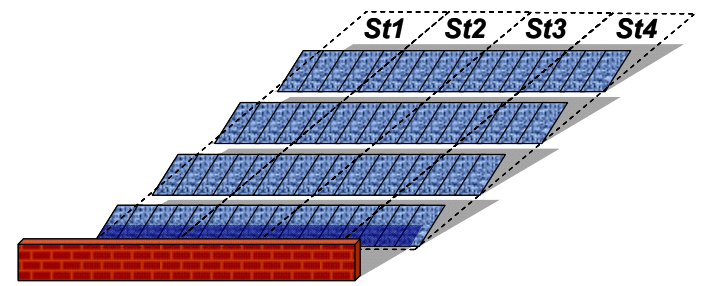

Fig. 14. The row arrangement and the balustrade in the first array - Configuration 1

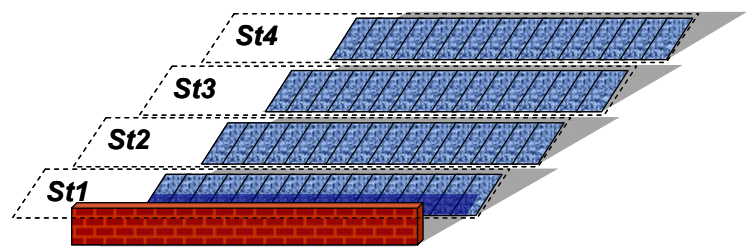

Fig. 15. The row arrangement and the balustrade in the first array - Configuration 2 


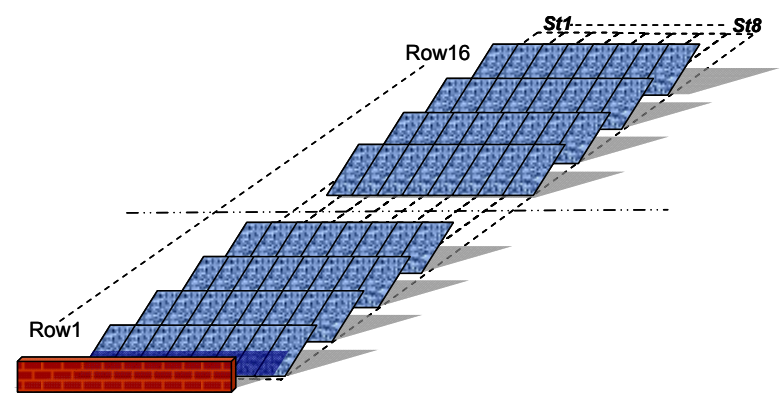

Fig. 16. The row arrangement and the balustrade in the second array - Configuration 3

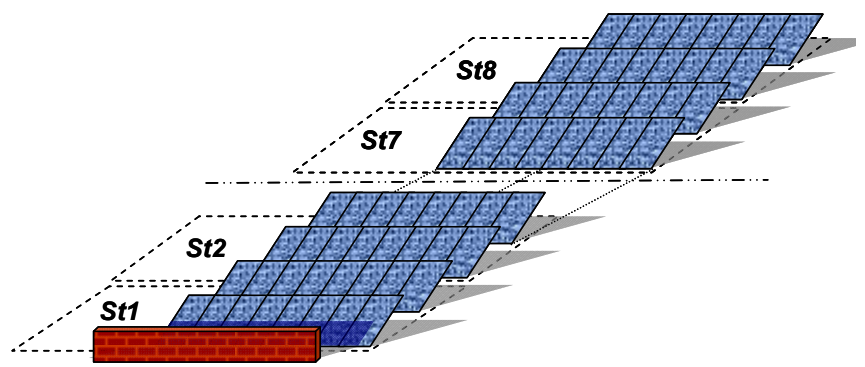

Fig. 17. The row arrangement and the balustrade in the second array - Configuration 4

The selected technology for the PV-module is the conventional poly-crystalline-silicon one with rated power of $215 \mathrm{~W}_{\mathrm{p}}$. The main specifications are presented in Table 2 (rated power $P_{\max }$, voltage $V_{M P P}$ and current $I_{M P P}$ at rated power, open circuit voltage $V_{O C}$, short circuit current $\mathrm{I}_{\mathrm{SC}}$, temperature coefficients of $\mathrm{V}_{\mathrm{OC}}, \mathrm{I}_{\mathrm{SC}}$, and normal operating cell temperature NOCT).

Notice that all the PV-modules are equipped with 3 bypass diodes, each protecting a group of 20 cells.

\begin{tabular}{ccc}
\hline $\mathrm{P}_{\max }=215 \mathrm{~W}_{\mathrm{p}}$ & $\mathrm{V}_{\mathrm{MPP}}=28.5 \mathrm{~V}$ & $\mathrm{I}_{\mathrm{MPP}}=7.55 \mathrm{~A}$ \\
\hline & $\mathrm{V}_{\mathrm{OC}}=36.3 \mathrm{~V}$ & $\mathrm{I}_{\mathrm{SC}}=8.2 \mathrm{~A}$ \\
$\beta_{\mathrm{Voc}}=-0.35 \% /{ }^{\circ} \mathrm{C}$ & $\mathrm{a}_{\mathrm{Isc}}=+0.05 \% /{ }^{\circ} \mathrm{C}$ \\
$\mathrm{NOCT}=48{ }^{\circ} \mathrm{C}$ &
\end{tabular}

Table 2. Specifications of the PV modules

As an example of the simulation outputs for each time step (15 min), Figure 18 illustrates the I-V curve, while Figure 19 shows the P-V characteristics of the array 1 with rated power $\mathrm{P}_{\mathrm{r}}=13.76 \mathrm{~kW}$ in the configurations 1,2 , and without shading in particular conditions of global irradiance $\mathrm{G}_{\mathrm{g}}$ (direct + diffuse), diffuse irradiance alone $\mathrm{G}_{\mathrm{d}}$, and ambient temperature. It is worth noting that the configuration 2 with shading concentrated on a single string is better that the other configuration with shading equally distributed on all the strings. Moreover, the action of the bypass diodes is clear in the abrupt variation of the derivative in the curve of configuration 1 (blue colour). 


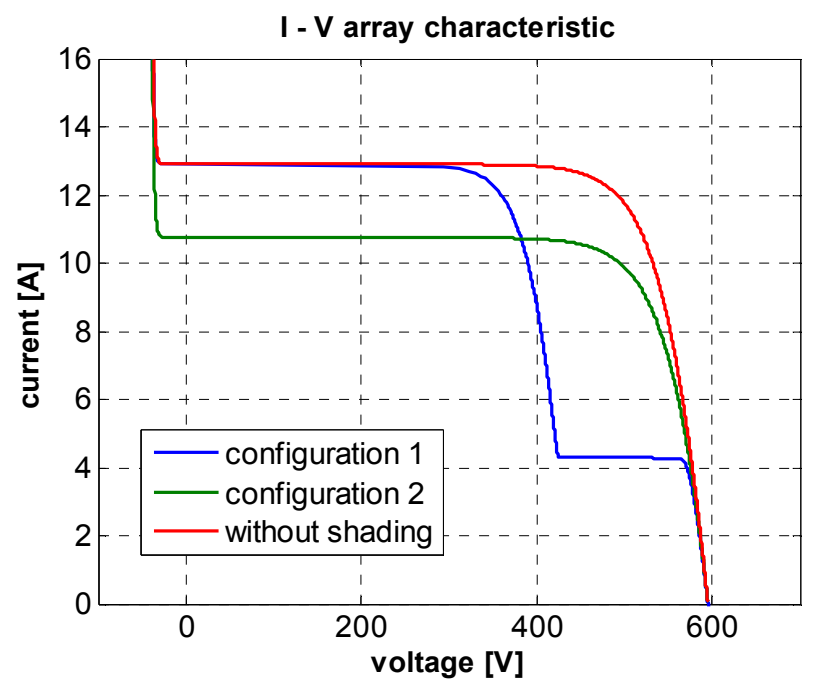

Fig. 18. The $\mathrm{I}-\mathrm{V}$ curve at $\mathrm{G}_{\mathrm{g}}=395 \mathrm{~W} / \mathrm{m}^{2}, \mathrm{G}_{\mathrm{d}}=131 \mathrm{~W} / \mathrm{m}^{2}$ and $\mathrm{T}_{\mathrm{a}}=4.1^{\circ} \mathrm{C}$

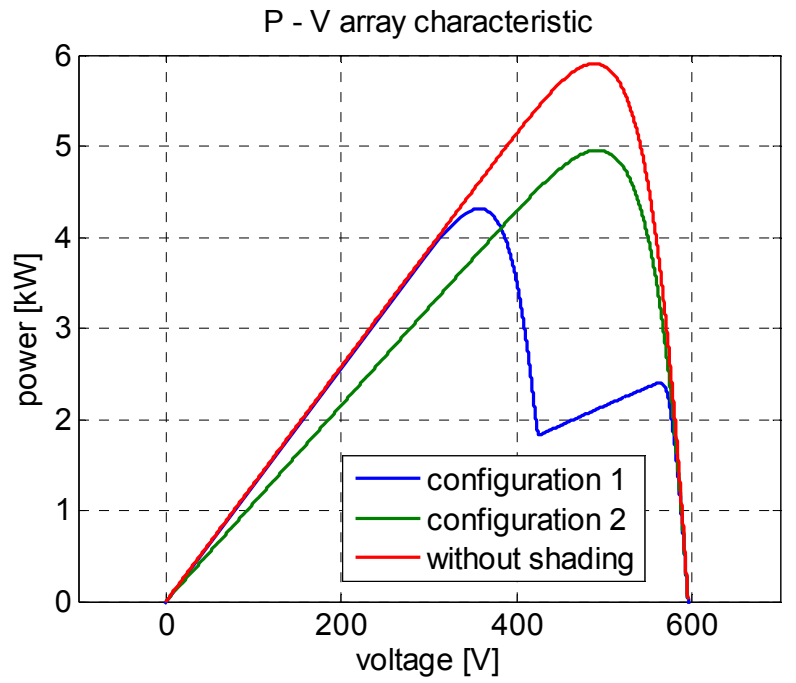

Fig. 19. The $P-V$ curve at $\mathrm{G}_{\mathrm{g}}=395 \mathrm{~W} / \mathrm{m}^{2}, \mathrm{G}_{\mathrm{d}}=131 \mathrm{~W} / \mathrm{m}^{2}$ and $\mathrm{T}_{\mathrm{a}}=4.1^{\circ} \mathrm{C}$

Furthermore, the simulation outputs provide also the daily power diagrams for both real (Fig. 20) and clear sky (Fig. 21) conditions for the configurations 1 and 2. It is possible to point out that the shading causes power losses in the afternoon, due to the azimuth of the PV array, and the produced energy is higher for configuration 2 with shading concentrated in a single string, as in the previous case. 


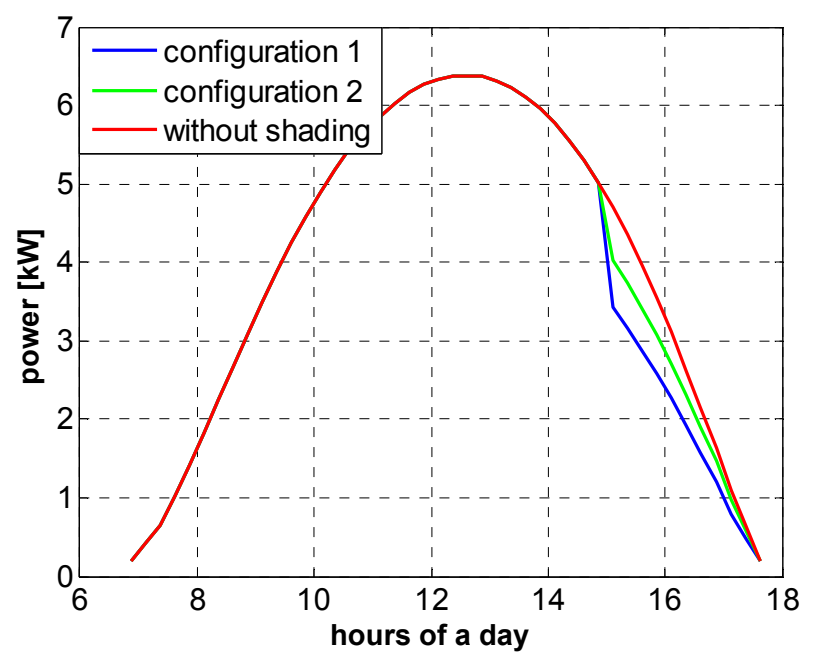

Fig. 20. The daily power diagrams in October for configurations 1 and 2 (Real Sky)

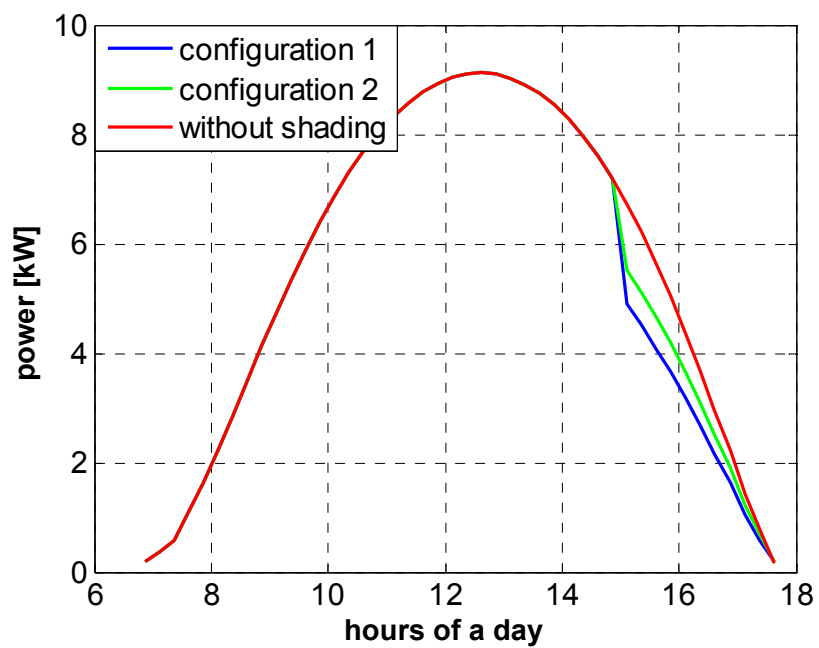

Fig. 21. The daily power diagrams in October for configurations 1 and 2 (Clear-sky)

Concluding the study on the two configurations of the first array, it can be stressed that the simulations on the average day of the months subject to shading effect give greater losses in configuration 1 than in configuration 2, both for real-sky days and clear-sky days. Obviously, the losses are maximum in December with values of $17.8 \%$ (Conf. 1) vs. 9.4\% (Conf. 2) but, if we consider the losses on yearly basis (including the months without shading), the mean value of losses is $2.5 \%$ (Conf. 1) vs. $1.3 \%$ (Conf. 2). Hence, in this case it is more profitable to adopt the module connection which allows to concentrate the shading in a single string. 


\begin{tabular}{cccccc}
\hline \multirow{2}{*}{ Day } & No shad. & \multicolumn{2}{c}{ Configuration 1 } & \multicolumn{2}{c}{ Configuration 2 } \\
\cline { 2 - 6 } & $\begin{array}{c}\text { Energy } \\
{[\mathrm{kWh}]}\end{array}$ & $\begin{array}{c}\text { Energy } \\
{[\mathrm{kWh}]}\end{array}$ & $\begin{array}{c}\text { Losses } \\
(\%)\end{array}$ & $\begin{array}{c}\text { Energy } \\
{[\mathrm{kWh}]}\end{array}$ & $\begin{array}{c}\text { Losses } \\
(\%)\end{array}$ \\
\hline Oct & 43.83 & 41.83 & 4.30 & 42.80 & 2.08 \\
Nov & 30.47 & 27.10 & 11.06 & 28.71 & 5.78 \\
Dec & 25.01 & 20.57 & 17.76 & 22.65 & 9.41 \\
Jan & 30.81 & 26.73 & 13.23 & 28.55 & 7.33 \\
Feb & 37.46 & 34.77 & 7.19 & 36.13 & 3.55
\end{tabular}

Table 3. Energies and losses in the shading patterns (Real sky)

\begin{tabular}{cccccc}
\hline \multirow{2}{*}{ Day } & No shad. & \multicolumn{2}{c}{ Configuration 1 } & \multicolumn{2}{c}{ Configuration 2 } \\
\cline { 2 - 6 } & $\begin{array}{c}\text { Energy } \\
{[\mathrm{kWh}]}\end{array}$ & $\begin{array}{c}\text { Energy } \\
{[\mathrm{kWh}]}\end{array}$ & $\begin{array}{c}\text { Losses } \\
(\%)\end{array}$ & $\begin{array}{c}\text { Energy } \\
{[\mathrm{kWh}]}\end{array}$ & $\begin{array}{c}\text { Losses } \\
(\%)\end{array}$ \\
\hline Oct & 61.30 & 58.65 & 4.33 & 59.68 & 2.65 \\
Nov & 47.15 & 41.81 & 11.33 & 43.56 & 7.61 \\
Dec & 40.08 & 32.75 & 18.29 & 35.04 & 12.54 \\
Jan & 44.74 & 38.66 & 7.19 & 40.64 & 3.55 \\
Feb & 56.87 & 52.70 & 7.32 & 54.17 & 4.75
\end{tabular}

Table 4. Energies and losses in the shading patterns (Clear sky)

Now, addressing the focus on the two configurations of the second array, it can be stressed that the simulations on the average day of the months subject to shading effect give slightly greater losses in configuration 3 than in configuration 4 for real-sky days whereas the opposite occurs for clear-sky days with higher values of losses. More in detail, in clear-sky conditions the losses are maximum in December with values of $4.69 \%$ (Conf. 3) vs. $6.24 \%$ (Conf. 4) but, if we consider the losses on yearly basis (including the months without shading), the mean value of losses is $0.65 \%$ (Conf. 3) vs. $0.64 \%$ (Conf. 4). Hence, with more complex structure of array and less amount of shading, it is almost equivalent either to concentrate the shading in a single string or to distribute equally in all the strings.

\begin{tabular}{cccccc}
\hline \multirow{2}{*}{ Day } & No shad. & \multicolumn{2}{c}{ Configuration 3 } & \multicolumn{2}{c}{ Configuration 4 } \\
\cline { 2 - 6 } & $\begin{array}{c}\text { Energy } \\
{[\mathrm{kWh}]}\end{array}$ & $\begin{array}{c}\text { Energy } \\
{[\mathrm{kWh}]}\end{array}$ & $\begin{array}{c}\text { Losses } \\
(\%)\end{array}$ & $\begin{array}{c}\text { Energy } \\
{[\mathrm{kWh}]}\end{array}$ & $\begin{array}{c}\text { Losses } \\
{[\mathrm{kWh}]}\end{array}$ \\
\hline Oct & 87.42 & 86.46 & 1.10 & 86.57 & 0.98 \\
Nov & 60.94 & 59.23 & 2.81 & 59.26 & 2.76 \\
Dec & 50.02 & 47.75 & 4.53 & 47.76 & 4.50 \\
Jan & 61.61 & 59.54 & 3.37 & 59.44 & 3.53 \\
Feb & 74.92 & 73.55 & 1.83 & 73.66 & 1.68
\end{tabular}

Table 5. Energies and losses in the shading patterns (Real-sky).

\begin{tabular}{cccccc}
\hline & \multicolumn{2}{c}{ No shad. } & \multicolumn{2}{c}{ Configuration 3 } & \multicolumn{2}{c}{ Configuration 4 } \\
\cline { 2 - 6 } Day & $\begin{array}{c}\text { Energy } \\
{[\mathrm{kWh}]}\end{array}$ & $\begin{array}{c}\text { Energy } \\
{[\mathrm{kWh}]}\end{array}$ & $\begin{array}{c}\text { Losses } \\
(\%)\end{array}$ & $\begin{array}{c}\text { Energy } \\
{[\mathrm{kWh}]}\end{array}$ & $\begin{array}{c}\text { Losses } \\
{[\mathrm{kWh}]}\end{array}$ \\
\hline Oct & 122.27 & 121.27 & 1.09 & 120.99 & 1.32 \\
Nov & 94.30 & 91.58 & 2.88 & 90.73 & 3.79 \\
Dec & 80.16 & 76.40 & 4.69 & 75.15 & 6.24 \\
Jan & 89.48 & 86.35 & 3.51 & 85.40 & 4.56 \\
Feb & 113.74 & 111.62 & 1.86 & 111.01 & 2.40
\end{tabular}

Table 6. Energies and losses in the shading patterns (Clear-sky). 


\subsection{Concluding remarks}

Since the PV-system designer does not take into account possible periodic shading when he decides the connections of the modules in the strings, the paper has discussed, by proper comparisons, various cases of shading pattern in PV arrays from multiple viewpoints: power profiles in clear days with 15-min time step, daily energy as a monthly average value for clear and cloudy days.

The simulation results prove that, with simple structure of the array and important amount of shading, it is better to limit the shading effect within one string rather than to distribute the shading on all the strings. Contrary, with more complex structure of the array and low amount of shading, it is practically equivalent to concentrate or to distribute the shading on all the strings.

Finally, in the simulation conditions the impact of the shading losses on yearly basis is limited to $1-3 \%$.

\section{Decrease of inverter performance for shading effect}

The last paragraph of this chapter deals with other consequences of the mismatch, because it has a significant impact also on the inverter performance and the power quality fed into the grid (Abete et al., 2005).

The real case of two systems installed in Italy within the Italian program "PV roofs" is presented. They have been built on the south oriented façades of the headquarters of two different municipal Companies. Due to the façade azimuth, besides the distances among the floors, a partial shading occurs during morning periods from April to September. The shading effect determined an important decrease of the available power. However the attention has been focused on the inverter performance, both at the DC and AC side in these conditions, during which experimental data have been collected. The DC ripples in voltage and current signals can be higher than $30 \%$, with a fundamental frequency within $40-80 \mathrm{~Hz}$; the Maximum Power Point Tracker (MPPT) efficiency resulted around 60\%, because the tracking method relied on the wrong assumption that the voltage at maximum power point (MPP) was a constant fraction of the open circuit voltage, while with shading the fraction decreased down to roughly 50\%; the Total Harmonic Distortion (THD) of AC current resulted higher than $20 \%$ with a great spread and presence of even harmonics, whereas the THD of voltage is slightly influenced by the shading; the power factor was within 0.75-0.95, due to the previous current distortion and the capacitive component, which becomes important in these conditions.

\subsection{Two real case PV systems built on façades}

Within an Italian grid connected PV Programme, two systems $\left(20 \mathrm{~kW}_{\mathrm{p}}\right.$ and $16 \mathrm{~kW}_{\mathrm{p}}$, respectively) have been installed in Torino on the south oriented façades of the headquarters of AMIAT (municipal company for the waste-materials management) and of "Provincia di Torino" public administration.

The first system consists of six PV plants, $3.3 \mathrm{~kW}_{\mathrm{p}}$ each: the array of a single plant counts 30 modules and supplies a single-phase inverter. The low-voltage three-phase grid is fed by two parallel connected inverters per phase $(230 \mathrm{~V}$ line to neutral wire). The second system consists of six PV plants, $2.6 \mathrm{~kW}_{\mathrm{p}}$ each: the array of a single plant counts 24 modules and 
supplies a single-phase inverter of the same model as in the first system. Also the scheme of grid connection is the same as in the previous system.

These PV systems are among the first examples of PV building integration in Italy, even if they are a retro-fit work: in fact, their modules behave as saw-tooth curtains (or "sun shields") providing a protection against direct sunlight, principally in summer season. Due to the façade azimuth $\left(\approx 25^{\circ}\right.$ west), besides the comparative distances among the rows of arrays, a partial shading effect occurs during morning periods from April to September. All the PV fields are involved by this partial shading during these periods except for the array 4, which is entirely located above the last floor in the first system (Fig. 22) and for the arrays 5 and 6, which are located on the roof, in the second system (Fig. 23).

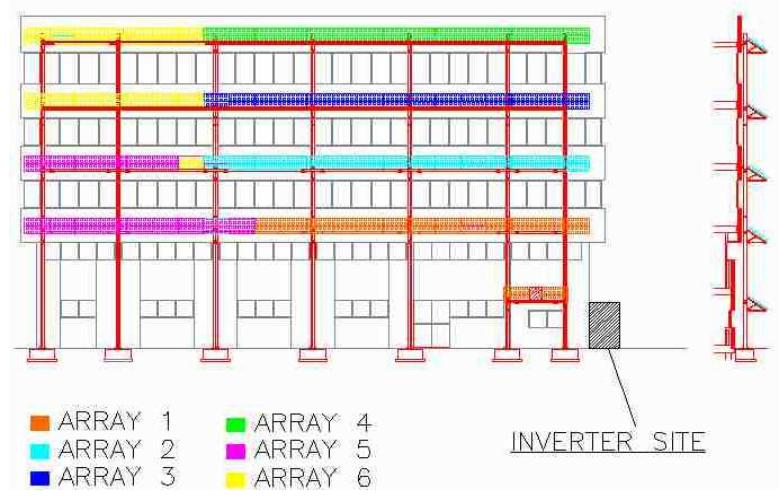

Fig. 22. PV arrays on the façade of the $1^{\text {st }}$ system.

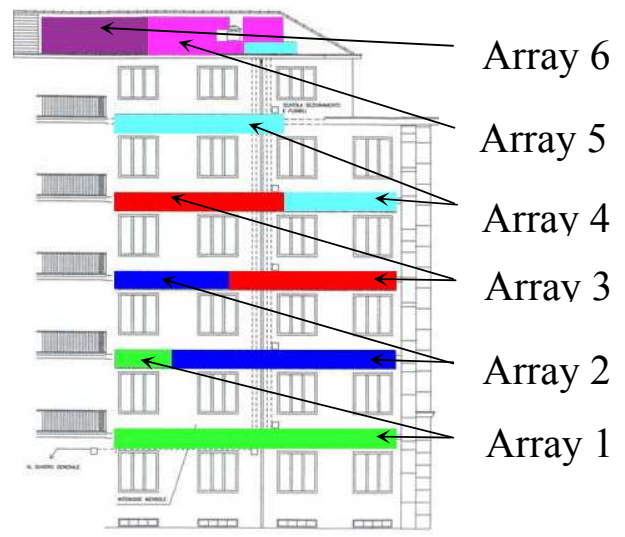

Fig. 23. PV arrays on the façade of the $2^{\text {nd }}$ system.

The amount of shaded array, the beginning and duration of these conditions, obviously, are depending on the calendar day. As well known, the shading effect, concentrated on 
some cells of a PV array, determines a mismatch of cell current-voltage I(V) characteristics, with an important decrease (only limited by the bypass diodes) of the available power; furthermore, the shaded cells can work as a load and the hot spots can rise. However the attention has been focused on the inverter performance, both at the DC side and at the AC side in shading conditions, during which experimental data have been collected.

\subsection{Parameters of inverter performance and their measurement system}

The inverter performance can be defined by the following parameters, besides the DC-AC efficiency:

- $\quad$ the ripple peak factors of DC voltage $V_{p p}=\frac{V_{\max }-V_{\min }}{V_{\text {mean }}}$ and current $I_{p p}=\frac{I_{\max }-I_{\min }}{I_{\text {mean }}}$;

- $\quad$ the MPP Tracker efficiency $\eta_{M P P T}=P_{D C} / P_{M A X}$ (how close to maximum power $P_{\text {MAX }}$ the MPPT is operating), where $P_{D C}$ is the input power of the inverter and $P_{\mathrm{MAX}}$ is the maximum power calculated on the current-voltage $\mathrm{I}(\mathrm{V})$ characteristic;

- the total harmonic distortion of grid AC voltage $T H D_{V}=\sqrt{V_{2}^{2}+V_{3}^{2}+\ldots+V_{n}^{2}} / V_{1}$ and AC current $T H D_{I}=\sqrt{I_{2}^{2}+I_{3}^{2}+\ldots+I_{n}^{2}} / I_{1}$, where $V_{1}\left(I_{1}\right), V_{2}\left(I_{2}\right), \ldots, V_{n}\left(I_{n}\right)$ are the harmonic r.m.s. values;

- the power factor $P F=P_{A C} /\left(V_{\text {trms }} \cdot I_{\text {trms }}\right)$, with $\mathrm{P}_{\mathrm{AC}}$ active power, $\mathrm{V}_{\text {trms }}$ and $\mathrm{I}_{\text {trms }}$ true r.m.s. voltage and current.

The measurements have been carried out by a Data Acquisition board (DAQ), integrated into a notebook PC. The real-time sampling has been performed at the sampling rate of 25.6 $\mathrm{kSa} / \mathrm{s}$, with a resolution of 12 bits. This rate corresponds to 512 samples per period at grid frequency of $50 \mathrm{~Hz}$, in such a way as to allow the calculation of the harmonics up to $50^{\text {th }}$. Three voltage probes and three current ones are used as a signal conditioning stage to extend the range of the measured quantities above the voltage range of $\pm 10 \mathrm{~V}$. These probes are equipped with operational amplifiers with low output resistance $(\approx 50 \Omega)$, for obtaining low time constants with the capacitance of the Sample \& Hold circuit in the DAQ board, which accepts up to eight input channels by its multiplexer.

A proper software, developed in LabVIEW environment, implements Virtual Instruments behaving as storage oscilloscope and multimeter for measurement of r.m.s. voltage (up to $600 \mathrm{~V}$ ), current (up to $20 \mathrm{~A}$ ), active power and power factor. The oscilloscope, in order to obtain the I(V) curves of the PV arrays, is equipped with a trigger system, useful for the capture of the transient charge of a capacitor. The multimeter also performs harmonic analysis for the calculation of THD by the Discrete Fourier Transform (DFT) and operates as data logger with user-selected time interval between two consecutive measurements.

\subsection{Distortion of waveforms in case of shading effect}

In case of shading effect, which causes the distortion of the I(V) shape, the ripples at the DC side of inverter increase and cannot be sinusoidal: the waveforms, thus, have harmonic content, as pointed out in (11) for the power, with a fundamental-harmonic frequency different from $100 \mathrm{~Hz}$ (double of grid frequency): 


$$
P_{D C}=V_{\text {mean }} \cdot I_{\text {mean }}+\sum_{k=1}^{n} V_{k} \cdot I_{k} \cdot \cos \varphi_{k}
$$

$\mathrm{V}_{\mathrm{k}}, \mathrm{I}_{\mathrm{k}}$ represent the r.m.s. values of harmonic voltage and current at the same frequency, whereas $\varphi_{\mathrm{k}}$ is the phase shift between voltage and current: here every $\cos \varphi_{\mathrm{k}}$ is negative and so the harmonics decrease the DC power.

A remarkable distortion arises also at the AC side of inverter with reference to the current: even harmonics, which cause that the positive half-wave is different from the negative halfwave, can be noticeable. The even harmonics do not contribute AC active power, since the grid voltage, generally, has only odd harmonics: the DC-AC efficiency, consequently, decreases.

Summarizing the previous items, the inverter parameters worsen with shading effect:

- the DC ripples can be higher than $10 \%$ and the waveforms have harmonic content, with a fundamental-harmonic frequency down to $30 \mathrm{~Hz}$, because the $\mathrm{I}(\mathrm{V})$ characteristics are distorted and multiple MPPs arise ;

- $\quad$ the MPPT efficiency can be lower than 95\%, because the tracking method, employed in the inverters under study, relies on the statement that the voltage $\mathrm{V}_{\mathrm{MPP}}$ at MPP is a constant fraction of the open circuit voltage, but with shading the fraction is lower;

- the THD of AC current can be higher than $10 \%$ with great spread and presence of even harmonics (especially the $2^{\text {nd }}$ one), whereas the THD of voltage is slightly influenced by the shading;

- the power factor can be lower than 0.9, due to both the previous distortion of AC current and a capacitive component, which becomes important when the active component is low, as in this case.

\subsection{Experimental tests to detect the inverter behaviour}

The experimental tests, presented in this section, include:

1. measurements of DC and AC waveforms by the oscilloscope on the inverters of the most shaded arrays of the first system (array 1 and 2) during the morning period and immediately after the shading;

2. measurements of AC waveforms by the oscilloscope on the inverters of the second system after the morning shading, in order to compare the behaviour, without shading, of inverters of the same model;

3. daily monitoring of the parameters of inverter performance at the AC side, by the data logger in three phase configuration, on the first system.

Concerning the item 1., the MPPT efficiency is obtained by two tests, carried out as close as possible because of the ambient conditions (irradiance and temperature) must be equal.

The first test determines the $\mathrm{I}(\mathrm{V})$ characteristics by a suitable method (transient charge of a capacitor. Hence, it is possible to calculate the maximum power $\mathrm{P}_{\mathrm{MAX}}$. As an example, Figure 24 shows ten $\mathrm{I}(\mathrm{V})$ curves of the array 2 during the morning evolution of the shading (from 9.50 to 11.35 in August). It is possible to note different conditions of irradiance: at 9.50 the shading is complete above all the PV modules (only diffuse radiation gives its contribution) and the $\mathrm{I}(\mathrm{V})$ shape is regular; from 10.25 to 10.35 the irradiance is not uniform, some modules begin to be subject to the beam radiation and the $I(V)$ shape has abrupt changes of derivative (bypass diodes action): the power, hence, decreases. 


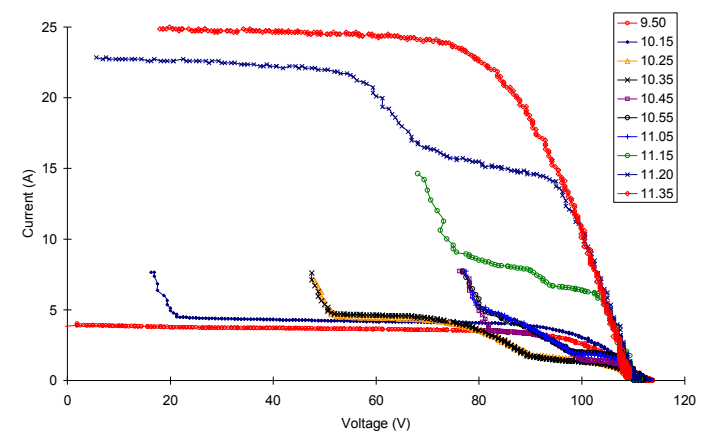

Fig. 24. I(V) curves of the array 2 during the shading.

Only after 11.05, when the most of modules are subject to beam radiation, the power begins again to increase; the shading, around 11.35, is vanishing. In Fig. 3 the I(V) curves are not complete because we have preferred to obtain the maximum accuracy of current measurement in the portion of $\mathrm{I}(\mathrm{V})$ that is used by the MPPT of the inverter (in this case 66$120 \mathrm{~V}$ is the voltage range of the MPPT).

The second test, for the same ambient conditions, provides the input signals of the inverter: voltage $v_{D C}(t)$, current $i_{D C}(t)$ and power $p_{D C}(t)$ affected by the ripples. It is worth noting that the amplitude and frequency of DC ripple can influence the normal work of the input DC filter and the DC-DC converter. Fig. 25 shows some profiles of DC current ripples, corresponding to the previous $\mathrm{I}(\mathrm{V})$ measurements: the waveforms have many changes of derivative with even harmonics, whereas the DC voltage ones have always a slow ascent and a steep descent (not represented here). This behaviour of $i_{D C}(t)$ can be responsible for higher losses in the iron inductor of DC-DC converter.

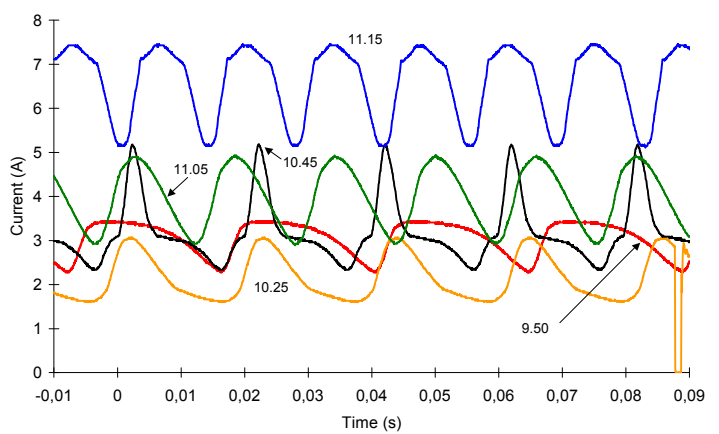

Fig. 25. DC current ripples during shading (inverter 2).

By combining the results of the two tests (Fig. 24 and Fig. 25), if the functions I(V) and $\mathrm{i}_{\mathrm{DC}}\left(\mathrm{v}_{\mathrm{DC}}\right)$ are plotted in the same diagram, it is possible to assess the operation of the MPPT in shading condition. As an example, Fig. 26 shows what happens at 10.25 in the inverter 2: the curves are not complete for the previous reason and the voltage $\mathrm{V}_{\mathrm{MPP}}<47 \mathrm{~V}$ (less than $43 \%$ of the PV open circuit voltage). The MPPT is not able to work in the absolute maximum 
power point (out of current scale here), due to the algorithm that imposes a voltage $V_{D C}$ equal to $78 \%$ of PV open circuit voltage. Moreover in this case $\mathrm{P}_{\mathrm{DC}}$ is $62 \%$ of the local MPP corresponding to $73 \mathrm{~V}$.

Table 7 summarizes the experimental results in terms of: the ripple frequency $f_{\text {ripple; }}$ the ripple indices of DC voltage $\mathrm{V}_{\mathrm{pp}}$ and current $\mathrm{I}_{\mathrm{pp}}$; the MPPT efficiency $\eta_{\text {MPPT }}$.

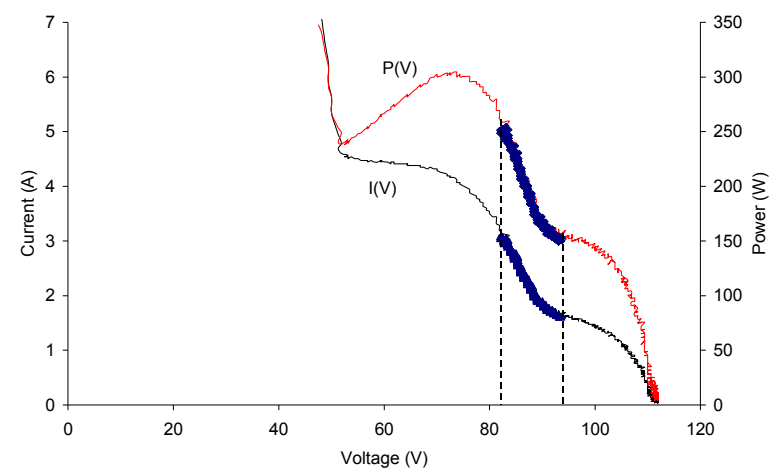

Fig. 26. Bad operation of MPPT in the inverter 2.

\begin{tabular}{ccccc}
\hline Hours & $\begin{array}{c}\mathbf{f}_{\text {ripple }} \\
(\mathbf{H z})\end{array}$ & $\begin{array}{c}\mathbf{V}_{\mathbf{p p}} \\
\mathbf{\%}\end{array}$ & $\begin{array}{c}\mathbf{I}_{\mathbf{p p}} \\
\mathbf{\%}\end{array}$ & $\begin{array}{c}\eta_{\text {MPPT }} \\
\mathbf{\%}\end{array}$ \\
\hline 9.50 & 41 & 27 & 38 & 89 \\
10.15 & 47 & 27 & 33 & 92 \\
10.25 & 48 & 13 & 69 & $<54$ \\
10.35 & 53 & 8.5 & 59 & $<49$ \\
10.45 & 50 & 20 & 89 & $<47$ \\
10.55 & 62 & 16 & 52 & $<56$ \\
11.05 & 64 & 16 & 51 & $<57$ \\
11.15 & 73 & 20 & 35 & $<58$ \\
11.20 & 80 & 9.2 & 4.5 & 81 \\
11.35 & 101 & 2.9 & 4.5 & 94
\end{tabular}

Table 7. The DC performance parameters (inverter 2)

Concerning the AC measurements of the items 1. and 2., the results show, during the shading, high distortion of current waveforms, which however does not worsen significantly the voltage waveforms $\left(\mathrm{THD}_{\mathrm{V}}\right.$ within the range of $\left.2-3 \%\right)$. The positive halfwaves are not all the same (on the time scale of few grid periods) and are very different from the negative half-waves (due to the even harmonics also present at the DC side). A capacitive component, enough remarkable, produces a phase shift with respect to the grid voltage. Figure 27 shows the voltage and current signals at 10.45 for inverter 2: the first positive half-wave has one sharp peak, whereas the last positive half-wave has two peaks, as it occurs for the negative half-waves.

The computation of the total harmonic distortion of AC current proves that the values are always higher than $15 \%$ (up to $22 \%$ ). With respect to the individual harmonics, the following 
remarks can be done: the second harmonic arises up to $8 \%$ in the first part (9.50-10.35), then vanishes; the seventh harmonic is the highest (10-14\%) for all the duration of the shading; the third harmonic maintains itself nearly constant at $6 \%$ until 11.20 , when it rises up to $10 \%$, that is the main component after the conclusion of shading; finally the fifth, ninth and eleventh harmonics maintain their selves around the 5\% level during the shading. Figure 28 summarizes these results in a histogram.

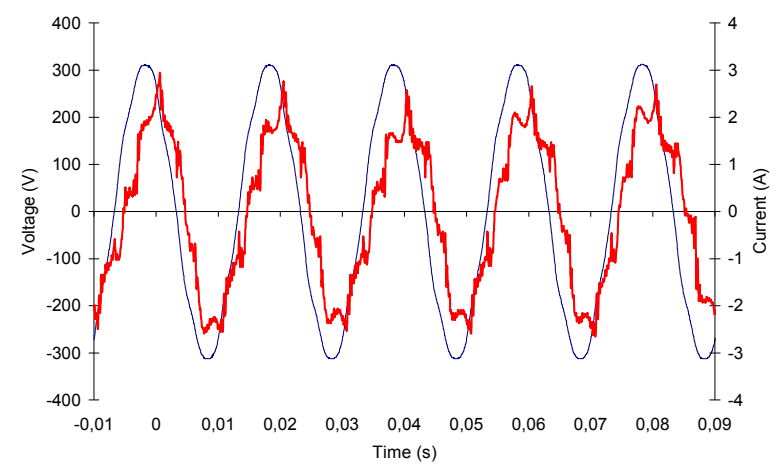

Fig. 27. AC waveforms of inverter 2 at 10.45 .

After the conclusion of the shading, all the six inverters of the first system have values of THD of AC current around $10 \%$, with the main component given by the third harmonic. In order to check whether this is the behaviour also for the inverters of the second system, the measurements of the AC waveforms, without the shading, have been carried out by the oscilloscope.

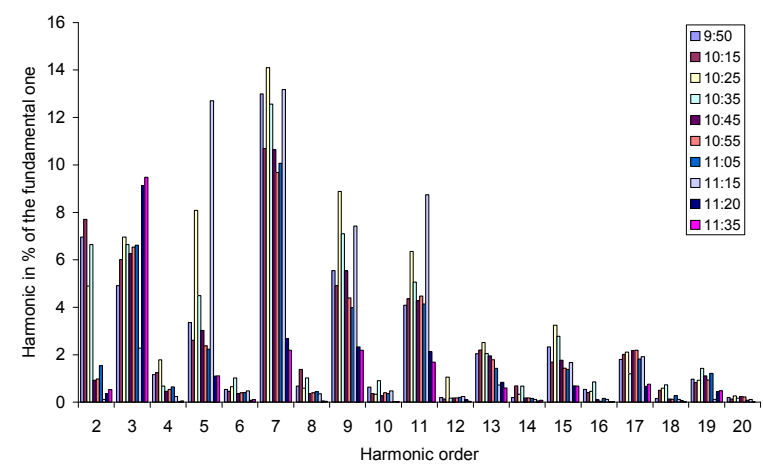

Fig. 28. Histogram of the harmonic currents (inverter 2).

As an example for the inverter 5, the waveforms of AC current and voltage are shown in Figure 29, in which it is worth noting that: no phase shift exists between voltage and current; a sharp peak, which causes a THD around $9 \%$, is detected in the current. Also the other inverters have confirmed the same behaviour for the current waveform and the harmonic distortion. 


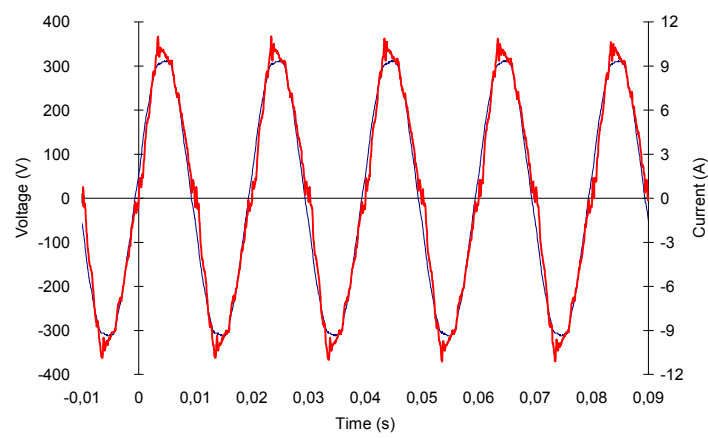

Fig. 29. AC waveforms of inverter 5 ( $2^{\text {nd }}$ system).

Concerning the item 3., by using the data logger, periodic measurements of r.m.s. voltage, current and power, besides harmonic analysis with THD, have been performed for each phase of the three-phase grid. In the first system, phase 1 supplies the currents of inverter 1 and 2 (the most shaded), phase 2 feeds the currents of inverter 3 and 4 (supplied by the only array without shading) and phase 3 feeds the currents of inverter 5 and 6. In Figure 30, relevant to a data acquisition in May, it is clear the shading effect until 13.00. During the shading, the main results are: the power factors $\mathrm{PF}_{1}$ and $\mathrm{PF}_{3}$ are continuously variable within the range $0.75-0.95$, due to not only the high harmonic distortion $\operatorname{THD}_{\mathrm{I}}(15-20 \%)$, but also the phase shift between voltage and current.

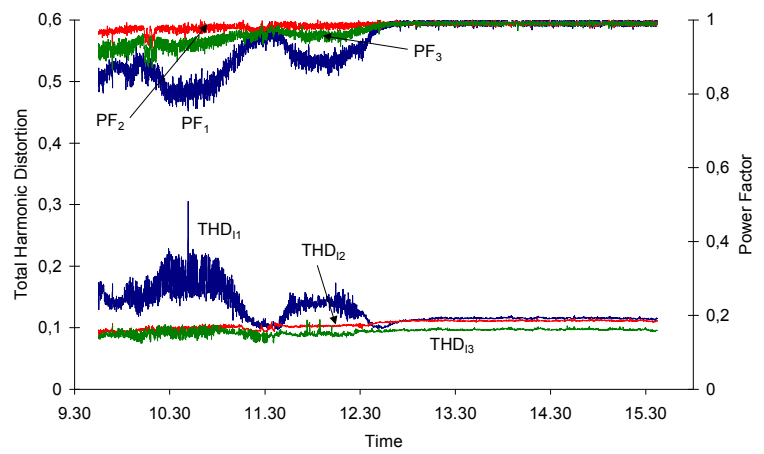

Fig. 30. Daily monitoring of PF and THD (1 ${ }^{\text {st }}$ system).

\subsection{Concluding remarks}

Concerning two grid connected PV systems, it has been described the negative influence, owing to shading effect of PV arrays, on the inverter performance both at the DC and the AC sides. The experimental results point out that:

- the DC ripples are higher than $30 \%$ and the waveforms have harmonic content, with a fundamental frequency within $40-80 \mathrm{~Hz}$;

- the MPPT efficiency is around $60 \%$, because the tracking method relies on the assumption that the voltage at MPP is a constant fraction of the open circuit voltage, but with shading the fraction decreases down to roughly $50 \%$; 
- the THD of AC current is higher than $20 \%$ with a great spread and presence of even harmonics, whereas the THD of voltage is slightly influenced by the shading;

- the power factor is within 0.75-0.95, due to the previous current distortion and the capacitive component, which becomes important in shading condition.

\section{References}

Abete, A.; Ferraris, L. \& Spertino, F. (1998). Measuring Circuits to detect Mismatching of the Photovoltaic cells or modules Current-Voltage Characteristics, IMEKO TC-4 Symposium on Development in Digital Measuring Instrumentation and $3^{\text {rd }}$ Workshop on ADC Modeling and Testing, pp. 313-315, Naples, Italy, September 17-18, 1998.

Abete, A.; Napoli, R. \& Spertino, F. (2003). A simulation procedure to predict the monthly energy supplied by grid connected PV systems, $3^{\text {rd }}$ World Conference on Photovoltaic Energy Conversion, pp. 1-4 (CD ROM), ISBN 4-9901816-3-8, Osaka, Japan, May 1118, 2003.

Abete, A.; Napoli, R. \& Spertino, F. (2005). Grid connected PV systems on façade "Sun Shields": Decrease of inverter performance for shading effect, 20th European Photovoltaic Solar Energy Conference, pp. 2135-2138, ISBN 3-936338-19-1, Barcelona, Spain, June 6-10, 2005.

Spertino, F.; Di Leo, P. \& Sumaili Akilimali, J. (2009). Optimal Configuration of module connections for minimizing the shading effect in multi-rows PV arrays, 24 th European Photovoltaic Solar Energy Conference, pp. 4136-4140, ISBN 3-936338-25-6, Hamburg, Germany, September 21-25, 2009.

Spertino, F. \& Sumaili Akilimali, J. (2009). Are manufacturing I-V mismatch and reverse currents key factors in large Photovoltaic arrays?, IEEE Transactions on Industrial Electronics, Vol. 56, No.11, (November 2009), pp. 4520-4531, ISSN 0278-0046. 


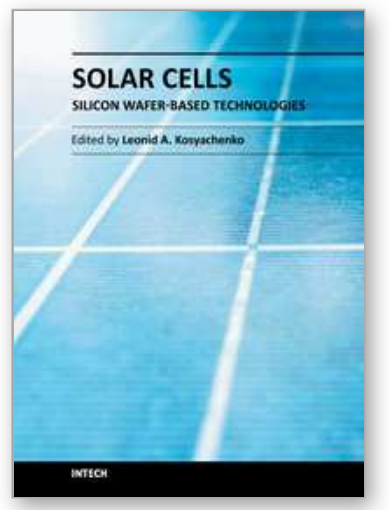

\author{
Solar Cells - Silicon Wafer-Based Technologies \\ Edited by Prof. Leonid A. Kosyachenko
}

ISBN 978-953-307-747-5

Hard cover, 364 pages

Publisher InTech

Published online 02, November, 2011

Published in print edition November, 2011

The third book of four-volume edition of 'Solar Cells' is devoted to solar cells based on silicon wafers, i.e., the main material used in today's photovoltaics. The volume includes the chapters that present new results of research aimed to improve efficiency, to reduce consumption of materials and to lower cost of wafer-based silicon solar cells as well as new methods of research and testing of the devices. Light trapping design in c-Si and $\mathrm{mc}$-Si solar cells, solar-energy conversion as a function of the geometric-concentration factor, design criteria for spacecraft solar arrays are considered in several chapters. A system for the micrometric characterization of solar cells, for identifying the electrical parameters of PV solar generators, a new model for extracting the physical parameters of solar cells, LBIC method for characterization of solar cells, non-idealities in the I-V characteristic of the PV generators are discussed in other chapters of the volume.

\title{
How to reference
}

In order to correctly reference this scholarly work, feel free to copy and paste the following:

Filippo Spertino, Paolo Di Leo and Fabio Corona (2011). Non-Idealities in the I-V Characteristic of the PV Generators: Manufacturing Mismatch and Shading Effect, Solar Cells - Silicon Wafer-Based Technologies, Prof. Leonid A. Kosyachenko (Ed.), ISBN: 978-953-307-747-5, InTech, Available from:

http://www.intechopen.com/books/solar-cells-silicon-wafer-based-technologies/non-idealities-in-the-i-vcharacteristic-of-the-pv-generators-manufacturing-mismatch-and-shading-eff

\section{INTECH}

open science | open minds

\author{
InTech Europe \\ University Campus STeP Ri \\ Slavka Krautzeka 83/A \\ 51000 Rijeka, Croatia \\ Phone: +385 (51) 770447 \\ Fax: +385 (51) 686166 \\ www.intechopen.com
}

\author{
InTech China \\ Unit 405, Office Block, Hotel Equatorial Shanghai \\ No.65, Yan An Road (West), Shanghai, 200040, China \\ 中国上海市延安西路65号上海国际贵都大饭店办公楼 405 单元 \\ Phone: +86-21-62489820 \\ Fax: $+86-21-62489821$
}


(C) 2011 The Author(s). Licensee IntechOpen. This is an open access article distributed under the terms of the Creative Commons Attribution 3.0 License, which permits unrestricted use, distribution, and reproduction in any medium, provided the original work is properly cited. 